\title{
Aplicación del principio iura novit curia en el arbitraje*
}

\author{
Oswaldo Hundskopf Exebio
}

\section{Introducción}

En la actualidad, el arbitraje se presenta como un mecanismo heterocompositivo de solución de controversias que, si bien mantiene algunos aspectos semejantes a la jurisdicción judicial, posee caracteres e instituciones propias que lo convierten en un método único y especial. Por ello, cuando nuestro ordenamiento jurídico regula las actuaciones arbitrales, las aleja taxativamente del proceso civil tal y como lo conocemos.

No obstante lo expuesto, resulta pertinente y necesario analizar cuáles son los principios jurídicos de la jurisdicción judicial aplicables al arbitraje, considerando su naturaleza sui géneris, entre ellos el iura novit curia, razón por la cual consideramos útil y oportuno reflexionar acerca de si este principio debe o no utilizarse en los arbitrajes de derecho.

Comentaremos, desde un punto de vista objetivo, acerca de su aplicabilidad dentro del arbitraje, considerando que esta máxima de derecho es empleada dentro del proceso civil, como reflejo del poder-deber

* Intervención del autor en la mesa redonda llevada a cabo en el III Seminario Nacional de Arbitraje Internacional - organizado por el Instituto Peruano de Arbitraje (IPA) - el 28 de noviembre del 2012, evento en el que se homenajeó a Jorge Santistevan de Noriega. 
de los jueces, para corregir o aplicar la norma jurídica cuando esta ha sido mal invocada u omitida.

Previamente nos referiremos al propósito de la Ley de Arbitraje actual - aprobada por Decreto Legislativo 1071 y vigente desde el 1 de setiembre del 2008 (en adelante, L de A) -, de desjudicializar el arbitraje, mencionando las diferencias existentes entre este y el proceso judicial, así como la normativa jurídica que reconoce la autonomía del arbitraje como método alternativo para la solución de conflictos, con lo que se le otorga un papel trascendental y de singular importancia en la solución de controversias.

Realizaremos también un breve comentario sobre los principios constitucionales que brindan, a las partes de un arbitraje, el derecho fundamental a la impugnación de las resoluciones o decisiones expedidas por el tribunal arbitral.

Por último, nos aproximaremos al principio iura novit curia, a su importancia, a su aplicabilidad dentro de arbitraje y a la jurisprudencia que motiva su reconocimiento dentro de las actuaciones arbitrales, entre otros aspectos que nos permitirán desarrollar nuestra posición favorable a su aplicación en el arbitraje.

\section{Propósito de desjudicializar el arbitraje}

Cuando anteriormente señalamos que nuestro ordenamiento jurídico aleja las actuaciones arbitrales de la regulación del actual Código Procesal Civil - vigente desde el 28 de julio de 1993-, lo hicimos porque así está previsto, pues en la décima disposición complementaria de la $\mathrm{L}$ de A se dispone que "las disposiciones procesales de esta norma, respecto de cualquier actuación judicial, prevalecen sobre las normas del Código Procesal Civil".

Otro dato relevante es que en toda la L de A ya no se habla del expediente, sino de las denominadas actuaciones arbitrales; tampoco se habla de procedimiento o de proceso arbitral, salvo - como única excepción accidental- la mención hecha en el inciso b del numeral 2 del artículo 47, con lo que se marca una distancia y se delimita un espacio propio para el arbitraje. Como otro ejemplo más está el caso del único recurso intraproceso que prevé la $\mathrm{L}$ de $\mathrm{A}$, el de reconsideración, que se denomina así - en lugar de reposición - en vista de la clara intención del legislador de alejarse de la terminología del proceso civil. 
Esta denominación genérica de actuaciones arbitrales no es casual; se funda en la doctrina y, en especial, en la práctica arbitral, y obedece a la forma en que se utiliza el arbitraje como un mecanismo heterocompositivo de solución de controversias y donde, en general, la autonomía de la voluntad inspira el convenio arbitral y condiciona el desarrollo del iter arbitral.

Asimismo, en su artículo 3, la L de A reconoce la autonomía de la jurisdicción arbitral respecto de la jurisdicción judicial, y su independencia frente a todo tipo de autoridad. Sin duda, dicho artículo es de importancia fundamental en la regulación y el desarrollo de los procesos arbitrales.

Tampoco puede dejar de reconocerse que el arbitraje se origina en un acuerdo de voluntades privadas (excepto cuando la ley lo dispone de manera imperativa, como por ejemplo, en el marco de las contrataciones con el Estado) y que, además, tiene características procesales, no obstante lo cual su naturaleza y características se pueden resumir en la función jurisdiccional que cumplen los árbitros, posición que es dominante y ha sido adoptada por la mayoría de quienes se han detenido a estudiar la naturaleza jurídica del arbitraje.

Si bien puede entenderse que la autoridad de los árbitros no es equivalente a la autoridad de los jueces - en virtud de la cual estos concluyen con la emisión de una sentencia en cada uno de los procesos judiciales sobre los cuales son competentes-, en el caso específico del arbitraje es incuestionable que existe una secuencia o sucesión de fases que se inicia con la petición del arbitraje, pasa necesariamente por una etapa postulatoria $-\mathrm{y}$, de ser necesario, por una o más de actuaciones probatorias - , para luego evaluarse los alegatos escritos y orales y concluir con la expedición de un laudo que expresa la decisión del tribunal, decisión a la que se arriba después de haber considerado los argumentos de las partes, haber analizado minuciosamente los fundamentos invocados por ellas y haber valorado los medios probatorios ofrecidos y aceptados de manera definitiva y con la motivación exigida por el inciso 1 del artículo 56 de la L de A.

Así pues, con el laudo se logra poner fin a una controversia para cuya solución ambas partes se han sometido a la decisión de privados o particulares, razón por la cual nos parece claro que si bien la intención del legislador ha sido alejarse de la nomenclatura tradicional, el arbitraje no deja de ser un tipo de proceso, aunque con características especiales. 
Es cierto que ahora la regulación de las actuaciones arbitrales se ha distanciado de la del proceso judicial, con la justificada intención de consolidar un espacio propio, pues debido a la recurrente invocación que se hacía de la primera disposición complementaria del Código Procesal Civil, según la cual todas sus disposiciones se aplicaban supletoriamente a los demás ordenamientos procesales, estas se solían utilizar y aplicar en los arbitrajes, lo que originaba, en la práctica, una judicialización del arbitraje en su desarrollo procesal. Esto es lo que se ha querido corregir o enmendar con la décima disposición complementaria de la $\mathrm{L}$ de $\mathrm{A}$, anteriormente mencionada.

\section{El arbitraje y la doctrina procesal}

Reconocido el carácter procesal del arbitraje, si bien este debe mantenerse independiente de las normas procesales civiles, opinamos que tal independencia no debe llevarse hasta el extremo de rechazar la doctrina procesal, pues al no poder integrarse los vacíos de las reglas pactadas o de la $\mathrm{L}$ de A con los principios arbitrales y los usos y costumbres de materia arbitral, se hace necesario recurrir a dicha doctrina, sin dejar de privilegiar los principios que regulan el arbitraje.

Conforme a la prelación establecida en artículo 34 de la L de A en los aspectos procedimentales, en primer lugar, se deberán aplicar las reglas aprobadas por las partes; en segundo lugar, se deberá aplicar el reglamento procesal especial al que voluntariamente las parte se han sometido; y luego serán los árbitros los que establezcan las reglas.

Apoyamos la tendencia que reconoce que el arbitraje posee una innegable trascendencia procesal, pues se trata de un proceso en el que se deducen y debaten pretensiones, se producen y valoran pruebas y se resuelven disputas sobre hechos y derechos; $\mathrm{y}$, como proceso, aun siendo dirigido y sustanciado por jueces privados y con reglas distintas, no puede escapar a esa ética que es común a todo proceso y que obliga a respetar las garantías fundamentales, como en el debido proceso, el derecho a la tutela jurisdiccional efectiva, el derecho a la defensa, el derecho a la igualdad procesal y el principio de contradicción, entre otros.

\section{Arbitraje: contrato o jurisdicción}

Si bien hay tendencias contractualistas o procesalistas que explican la naturaleza jurídica del arbitraje, ambas coinciden en su función jurisdic- 
cional, la que se da no solo por la jerarquía de la norma constitucional que se la reconoce, sino porque los árbitros, al resolver los conflictos, declaran el derecho que asiste a la parte cuyas pretensiones amparan, y porque la emisión del laudo constituye un acto jurisdiccional.

$\mathrm{Al}$ respecto, consideramos pertinente recalcar que los árbitros gozan de notio, vocatio y resolutio, pero carecen de coercio y executio, salvo cuando, por la naturaleza de la controversia, las propias partes, dentro del marco de la ley, les otorguen a los árbitros facultades de ejecución.

Nuestra Constitución Política reconoce la existencia de una jurisdicción arbitral independiente al establecer, en su artículo 139, que "no existe ni puede establecerse jurisdicción alguna, independiente, con excepción de la militar y la arbitral". Asimismo, en su artículo 62 establece que "los conflictos derivados de la relación contractual solo se solucionan en la vía arbitral o en la judicial, según los mecanismos de protección previstos en el contrato o contemplados en la ley."

Además, la resolución del Tribunal Constitucional, del 28 de febrero del 2006, recaída en el exp. 6167-2005, reconoce plenamente la independencia jurisdiccional del arbitraje cuando expresa: "Este tribunal reconoce la jurisdicción del arbitraje y su plena y absoluta competencia para conocer y resolver las controversias sometidas al fuero arbitral sobre materias de carácter disponible, con independencia jurisdiccional, y por tanto sin intervención de ninguna autoridad administrativa o judicial ordinaria".

En consecuencia, podemos concluir que la jurisdiccionalidad del arbitraje está reconocida constitucionalmente, a lo cual hay que agregar y precisar que:

[...] el arbitraje no puede entenderse como un mecanismo que desplaza al Poder Judicial, ni tampoco como su sustitutorio, sino como una alternativa que contempla el sistema judicial, puesta a disposición de la sociedad para la solución pacífica de las controversias, y que constituye una necesidad, básicamente para la solución de conflictos patrimoniales de libre disposición y, sobre todo, para la resolución de controversias que se generen en la contratación internacional. ${ }^{1}$

1 STC 6167-2005-PHC/TC, de 28 de febrero del 2006, fundamento 10. 


\section{Principios y derechos constitucionales}

Si bien el arbitraje es una jurisdicción especial e independiente reconocida por la Constitución Política en su artículo 139, el ejercicio de sus atribuciones debe hacerse observando los principios y derechos constitucionalmente reconocidos, y debe quedar sujeto al control judicial posterior mediante el recurso de anulación. Ello no solo responde a la razonabilidad jurídica, sino que también ha sido precisado por el Tribunal Constitucional:

9. Asimismo, la naturaleza de jurisdicción independiente del arbitraje no significa que establezca el ejercicio de sus atribuciones con inobservancia de los principios constitucionales que informan la actividad de todo órgano que administra justicia, tales como el de independencia e imparcialidad de la función jurisdiccional, así como los principios y derechos de la función jurisdiccional. En particular, en tanto jurisdicción, no se encuentra exceptuada de observar directamente todas aquellas garantías que componen el derecho al debido proceso (resaltado nuestro). ${ }^{2}$

En consecuencia, a pesar de su independencia jurisdiccional, reconocida por la Constitución, existe una reserva de facultades jurisdiccionales hecha por el Tribunal Constitucional, producto del cumplimiento de una de sus principales funciones: la protección de los derechos fundamentales de las partes que intervienen en un proceso judicial, arbitral o militar.

Por lo tanto, consideramos que la jurisdicción arbitral no se encuentra exceptuada de observar directamente todas las garantías que integran el derecho al debido proceso, el cual constituye el primero de los principios constitucionales de la administración de justicia, pues permite a todo ciudadano el libre e irrestricto acceso a los tribunales de justicia con el objeto de someter su derecho en disputa a la resolución del órgano jurisdiccional, para que ella sea dirimida con certeza y eficacia.

Antes de desarrollar el principio iura novit curia como tema principal, dentro de las garantías que integran el debido proceso nos interesa resaltar el derecho de impugnación, ya que su ejercicio es un derecho fundamental especialmente regulado y garantizado en el fuero arbitral.

2 STC 6167-2005-PHC/TC, de 28 de febrero del 2006, fundamento 9. 


\subsection{El derecho de impugnación en el arbitraje}

Mediante la impugnación, una persona que se considera afectada con una decisión o resolución puede cuestionarla y pedir su revocación o nulidad, empleando las vías o medios previstos en la ley. Como se ha mencionado, la jurisdicción arbitral no está exceptuada de observar todas las garantías que integran el derecho al debido proceso, entre las que se encuentra el derecho de impugnación; en consecuencia, el ejercicio de este último es un derecho fundamental especialmente regulado y garantizado en el fuero arbitral.

La jurisdicción arbitral tiene sus propios mecanismos y procedimientos para ejercerlo, tanto dentro del arbitraje como a la terminación de este. Dichos mecanismos permiten ejercitarlo mediante alguna forma de impugnación, bien como recursos arbitrales, bien como recursos judiciales y acciones constitucionales. Se plantean en tres diferentes vías:

\footnotetext{
a) Dentro del arbitraje: recurso de reconsideración.

b) Como recursos judiciales: anulación y en

Tres vías $\longrightarrow$ casación en su caso.

c) Como acciones constitucionales: proceso de amparo, recurso de agravio constitucional y recurso de queja.
}

El derecho de impugnación garantiza la pluralidad de instancias prevista en el numeral 6 del artículo 139 de la Constitución Política del Perú.

\section{El principio iura novit curia}

\subsection{Antecedentes}

Este principio es de origen impreciso: data de los siglos XIII y/o XIV, de manera que si bien se encuentra históricamente implícito en la mayoría de sistemas jurídicos, su reconocimiento y formulación legislativa en los diferentes sistemas jurídicos del mundo se ha dado en los últimos siglos.

Las referencias al iura novit curia lo presentan como postulado o aforismo jurídico, pero preferimos entenderlo como principio jurídico - de evolución lenta y extensa - que encuentra su fundamento en la abstrac- 
ción lógica de que los jueces conocen el derecho o norma jurídica, presupuesto que todo sistema jurídico debe contener.

En la actualidad, los sistemas jurídicos que han reconocido en forma expresa este principio se han adecuado a la moderna concepción del proceso - que supera a la concepción individual-liberal, notoriamente encasillada en excesivos formalismos - , brindándole así, al juez, posibilidades nuevas, más acordes a los hechos y al derecho que deberá aplicar en el momento de resolver los conflictos de los particulares.

Estas posibilidades y ventajas que se brindan al juez mediante la aplicación del principio iura novit curia resultan ser fundamentales, pues le permiten aplicar el derecho pertinente así este haya sido mal invocado o no lo haya sido por las partes, sin tener que esperarse las modificaciones y creaciones legislativas que, lógicamente, tomarían un tiempo muy extenso.

Iura novit curia significa "el juez conoce el derecho", y se refiere a la invocación de las normas jurídicas que sirven de fundamento a las pretensiones mantenidas por las partes dentro del proceso. ${ }^{3}$ Entonces, el juez puede alterar el fundamento jurídico de la pretensión de la parte, pero no puede alterar la naturaleza ni la articulación de la pretensión misma. ${ }^{4}$

En nuestro ordenamiento legal este principio está recogido en el artículo VII del título preliminar del Código Civil, conforme al cual "los jueces tienen la obligación de aplicar la norma jurídica pertinente, aunque no haya sido invocada en la demanda".

Con arreglo al principio iura novit curia, es el juez, como titular de la potestad jurisdiccional, el que tiene el poder-deber de proporcionar el derecho aplicable al proceso, con prescindencia de la respectiva invocación de las partes conforme a las pretensiones planteadas. Este principio se funda, como se ha mencionado, en la presunción lógica de que el juez está capacitado e instruido para conocer el derecho y, en consecuencia, no se encuentra vinculado por las calificaciones de las partes, salvo el límite de respetar el principio de congruencia.

3 “Díez-Picazo, Luis y Antonio Gullón, op. cit., p. 225. Se afirma que el iura novit curia 'era un aforismo manejado ya por los antiguos glosadores, tan aficionados a compendiar la sabiduría jurídica de su tiempo en aforismos y brocados de síntesis jurídica en los que se ha inspirado la ciencia dogmática de nuestra época'"'. Ver Silva Vallejo (1985: 478).

4 “Díez-Picazo, Luis y Antonio Gullón, op. cit., p. 227”. Ver Silva Vallejo (1985). 
Así concebido, la actitud del juez frente al derecho muestra tres características fundamentales: 1) su deber de conocerlo y, por tanto, de estudiarlo; 2) su facultad de interpretarlo; y 3) su libertad para aplicarlo.

A decir de Monroy Gálvez:

[...] el Código Civil incorpora una norma de carácter eminentemente procesal, que es concordante con el artículo VII del Código Procesal Civil. En términos generales, el aforismo contiene una actividad que corresponde al juez durante la sustanciación de un proceso, generalmente, en la etapa de decisión o sentencia, que constituye en calificar jurídicamente el conflicto de intereses o incertidumbre jurídica que constituye la pretensión discutida en el proceso. Esta función de calificar le sobreviene al juez como consecuencia de cualquiera de estas situaciones: porque las partes no lo hicieron o porque en opinión del juez, lo hicieron erróneamente (2007: 58).

En efecto, el Código Procesal Civil regula este supuesto, pero le brinda una definición más completa y detallada que la consagrada por el Código Civil; en su artículo VII del título preliminar establece: "el juez debe aplicar el derecho que corresponda al proceso, aunque no haya sido invocado por las partes o lo haya sido erróneamente. Sin embargo, no puede ir más allá del petitorio ni fundar su decisión en hechos diversos de los que han sido alegados por las partes".

A su vez, el inciso 2 del artículo 184 de la Ley Orgánica del Poder Judicial - cuyo Texto Único Ordenado fue aprobado por D. S. 017-93JUS, del 2 de junio de 1993- prescribe que son deberes de los magistrados: "Administrar justicia aplicando la norma jurídica pertinente, aunque no haya sido invocada por las partes o lo haya sido erróneamente".

\subsection{Funciones de este principio}

a) Función supletoria. Cuando las partes han omitido invocar el derecho aplicable o los fundamentos de derecho que sustenten la demanda y los demás actos postulatorios, el juez suple entonces la omisión de las partes, aplicando el derecho que corresponde.

La obligación del juez de aplicar la norma jurídica pertinente, aunque no haya sido invocada en la demanda, comprende también la correcta calificación de la acción de acuerdo a su naturaleza, aun cuando el accionante le haya dado designación distinta (Exp. 1745-92; 22.7.1993). 
b) Función correctora. El juez debe aplicar la norma jurídica pertinente cuando las partes han invocado erróneamente el derecho que sustenta sus peticiones.

Por ejemplo, cuando se plantea la reivindicación de herencia debe entenderse, por aplicación del principio de iura novit curia, que se demanda la petición de herencia. Esta petición es procedente, ya que el derecho del actor a que se le reconozca la parte proporcional de los bienes materia del condominio está acreditado, de manera que previa liquidación de la misma, se le debe entregar la porción correspondiente (Cas. 1242-97-Ica; 12.2.1999).

\subsection{Límites para su aplicación}

a) La congruencia. Es el límite esencial, por el cual sólo los hechos que las partes aporten pueden formar parte del material de conocimiento del juez. Para aplicar este principio tiene que haber congruencia entre el petitorio, los fundamentos de hecho invocados y la prueba actuada en el proceso, por lo que el juez no puede fundamentar la sentencia en casos o supuestos de hecho distintos a los invocados por las partes durante el proceso.

b) El objeto de la pretensión. Tanto el petitum (el efecto jurídico) como la causa petendi (el título o fundamento) no pueden ser modificados por el juez, de manera que este no puede resolver en la sentencia algún punto o tema que no haya estado previsto originalmente en el petitorio de la demanda, contestación y/o reconvención.

c) La prescripción. Necesariamente debe ser invocada por la parte y, una vez alegada, le corresponde al juez hacer la calificación correspondiente. La caducidad sí puede ser declarada de oficio por este, pues el principio iura novit curia así lo permite.

Opinamos que este principio se aplica tanto en los procesos contenciosos como en los no contenciosos, pues si bien la norma señala de modo expreso que se aplica a los primeros, consideramos que también en los procesos no contenciosos las partes pueden omitir invocar o, en todo caso, pueden invocar erróneamente el derecho aplicable a su petición, en cuyo supuesto el juez deberá aplicar el derecho que corresponda. 


\subsection{Aplicación del iura novit curia}

a) Jurisprudencia argentina

Víctor Roberto Obando Blanco recoge diversos pronunciamientos jurisprudenciales en la publicación de su obra Estudios de derecho procesal civil, donde hace un extenso análisis del principio iura novit curia.

En lo que sigue, podrá observarse que los tribunales argentinos han venido realizando desde hace muchos años un invalorable aporte en el desarrollo de este principio.

Con respecto a la relación jurídica procesal, han manifestado:

El principio de iura novit curia no autoriza a que el juez altere los términos en que quedó trabada la relación procesal mediante los escritos de demanda, reconvención y sus respectivas contestaciones [...]. ${ }^{5}$

Asimismo, con relación a la suplencia del derecho, han dicho:

El principio "iura novit curia" se refiere al derecho que el juez puede suplir, pero no a los fundamentos de la "legitimatio ad causam", que no pueden ser alterados ni subsanados por el juzgador. ${ }^{6}$

Nuestro pronunciamiento no es ritual, por lo que, individualizada con claridad y exactitud la cosa objeto de la acción y expuestos los hechos conducentes, ha de estarse a la verdadera pretensión de las partes, y el juez aplicará el derecho que corresponda [...]. ${ }^{7}$

Dentro de una correcta hermenéutica contractual, incumbe al juzgador en última instancia y de conformidad con el principio "iura novit curia" determinar la verdadera naturaleza del contrato que liga a las partes, prescindiendo en tal sentido de las palabras empleadas por ellas y de la calificación que le acuerden, cuando esta no se compadece con la verdadera esencia del plexo convencional. ${ }^{8}$

5 Revista de Jurisprudencia Argentina, 2 de octubre de 1953, t. 1954-I, Buenos Aires, pp. 153-159. Citado por Obando Blanco (1997: 171).

6 Revista Jurídica Argentina La Ley, 19 de abril de 1951, abril-junio t. 62, Buenos Aires, pp. 892-901. Citado por Obando Blanco (1997: 171).

7 Revista Jurídica Argentina La Ley, 14 de junio de 1966, octubre-diciembre, t. 124, Mar del Plata, pp. 90-91. Citado por Obando Blanco (1997: 172).

8 Revista Jurídica Argentina La Ley, 5 de febrero de 1981, t. 1981-B, Buenos Aires, pp. 426-428. Citado por Obando Blanco (1997: 173). 
Compete al tribunal interviniente la calificación jurídica de las articulaciones sometidas a juzgamiento en virtud del principio según el cual es el juez quien proporciona el derecho aplicable a todo asunto traído a su conocimiento, con prescindencia de la respectiva invocación de los litigantes (iura novit curia). ${ }^{9}$

En relación con la calificación de la acción, han establecido:

En la calificación de la acción y la determinación de la norma, la actividad del juez no está condicionada por la voluntad de las partes (iura novit curia), de tal modo que puede rectificar la calificación que ellas hicieron o aplicar un precepto distinto al invocado. ${ }^{10}$

Asimismo, con respecto a la naturaleza del verdadero carácter de la relación jurídica que vincula a las partes, los tribunales argentinos han concluido:

El principio de que el juez debe fallar conforme a las acciones deducidas en la demanda, no le impide establecer el verdadero carácter de la relación jurídica que vincula a las partes, cualquiera sea la denominación que estas le hayan dado [...]. ${ }^{11}$

Con respecto a los límites a la aplicación del principio iura novit curia, han decidido:

Si bien el aforismo iura novit curia indica literalmente que como el juez conoce el derecho no se encuentra vinculado por las clasificaciones de los justiciables, existe un límite para ello, pues por más amplias que sean las potestades de determinar el derecho aplicable, no puede variar los términos del reclamo, ya que siempre ha de respetar el referido postulado de congruencia. ${ }^{12}$

La determinación de las normas jurídicas aplicables es cuestión que concierne al juzgador, quien debe atenerse exclusivamente a su cono-

9 Revista Jurídica Argentina La Ley, 11 de noviembre de 1981, t. 182-C, Buenos Aires, pp. 70-71. Citado por Obando Blanco (1997: 173).

10 Revista Jurídica Argentina La Ley, 3 de abril de 1959, abril-junio, t. 94, Buenos Aires, pp. 303-306. Citado por Obando Blanco (1997: 172).

11 Revista Jurídica Argentina La Ley, 20 de abril de 1967, julio-septiembre, t. 127, Argentina, pp. 290-292. Citado por Obando Blanco (1997: 172).

12 Revista Jurídica Argentina La Ley, 24 de diciembre de 1985, t. 1986-B, Buenos Aires, pp. 14-15. Citado por Obando Blanco (1997: 174). 
cimiento del orden jurídico vigente, con prescindencia de las afirmaciones o argumentaciones de orden legal formuladas por las partes.

Cada acción se identifica por el hecho que la genera y no por la acertada o errónea cita del precepto legal invocada en la demanda, ni por la designación con la que la haya individualizado el demandante, máxime si se atiende a que las normas que obligan al juez a fallar conforme a las acciones sustentadas, no obstan para que califique la relación jurídica con arreglo al principio iura novit curia. ${ }^{13}$

b) En sede constitucional nacional

Sección 1.01 El aforismo iura novit curia y su aplicación en los procesos constitucionales [...].

5. Distinto, pero también importante para una eficiente protección de derechos, es el caso del aforismo iura novit curia, contemplado en los artículos VII del Título Preliminar del Código Civil y del Código Procesal Civil, aplicable supletoriamente a los procesos constitucionales, conforme al artículo 63 la Ley N. ${ }^{\circ} 26435$. Aquel precepto establece que "el juez debe aplicar el derecho que corresponda al proceso, aunque no haya sido invocado por las partes o lo haya sido erróneamente $^{14}[\ldots]^{\prime \prime}$.

Dicho aforismo, literalmente significa "El Tribunal conoce el derecho", y se refiere a la invocación o no invocación de las normas jurídicas que sirven de fundamento a las pretensiones esgrimidas por las partes dentro de un proceso. Al respecto, Luis Díez Picazo y Antonio Gullón (Sistema de Derecho Civil: Madrid, Tomos, 1982, pág. 227) exponen que el juez puede alterar el fundamento jurídico de la pretensión de la parte [...].

6. Aun cuando este no sea el principio que pudiera ser que viene siendo aplicable a este caso, consideramos importante referirnos a él, a fin de determinar el contenido de sus alcances. Así, a diferencia de las situaciones resueltas sobre la base de la aplicación del principio

13 Revista Jurídica Argentina La Ley, 26 de mayo de 1987, t. 1988-A, Buenos Aires, pp. 84-87. Citado por Obando Blanco (1997: 175).

14 Exp. 0569-2003-AC/TC, Lima, 5 abril del 2004. 
de suplencia de queja deficiente, por aplicación del aforismo iura novit curia, el juez tiene el poder-deber de identificar el derecho comprometido en la causa, aun cuando no se encuentre expresamente invocado en la demanda. De este modo el juez, como director del proceso, dice el derecho antes de emitir sentencia (Taipe Chávez, Sara. Algunas Reflexiones sobre el iura novit curia. En: Derecho Procesal. II Congreso Internacional. Lima 2002, pág. 215), lo que no implica, en ningún caso, la modificación del objeto de la pretensión o de los términos de la demanda; es decir, que ello no puede suponer fundar su decisión en hechos diversos de los que han sido alegados por las partes.

\section{c) En sede casatoria}

En la jurisprudencia casatoria y civil, tanto en el derecho comparado como en el nuestro, son múltiples los pronunciamientos sobre la aplicación del principio iura novit curia. Nuestra Corte Suprema se ha pronunciado por la correcta o incorrecta aplicación de este principio cuando, en este último caso, los jueces de instancia han ido más allá del petitorio o se han fundado en hechos diversos de los que han sido alegados. Algunos ejemplos son:

- Cas. 1708-96/ Lima, publicada el 4 de junio de 1998:

En cuanto al derecho aplicable, es precisamente en aplicación del artículo séptimo del Título Preliminar del Código Procesal Civil, que recoge el principio iura novit curia, que el juez aplica el derecho, aun cuando no haya sido invocado por las partes, por lo que la invocación de una norma legal, siempre será una cuestión de iure, un fundamento de hecho, y dado su carácter general, su aplicación está mas allá de la invocación que de ella hagan las partes, por lo que considerar que la aplicación de una norma legal es una cuestión de hecho, como pretende la recurrente, es impropio.

- Cas. 1623-99/ Jaén, publicada el 10 de noviembre de 1999:

El aforismo iura novit curia solamente es aplicable para subsanar o corregir los fundamentos de derecho de la demanda, pero no puede extenderse a modificar el petitorio de la misma [...]. 
- Cas. 1634-2000-Cajamarca, publicada el 30 de setiembre del 2003:

En el presente caso, la norma cuya inaplicación fue denunciada (inciso 7 del artículo 132 de la Ley General de Sociedades) no establece ninguna relación de causalidad entre este proceso y su contenido. Sin embargo, en aplicación del artículo VII del Título Preliminar del Código Procesal Civil, se determina que la inaplicación del inciso 7 del artículo 132 a que se refiere el recurso de casación es el que corresponde a la Ley № 26702, Ley General del Sistema Financiero y del Sistema de Seguros y Orgánica de la Superintendencia de Banca y Seguros (Ley de Bancos). ${ }^{15}$

- Cas. 0222-2001-Huánuco, publicada el 1 de febrero del 2002:

No obstante el error en que incurre la recurrente al citar la causal de "interpretación errónea de una norma de derecho material", cuando la norma citada es de derecho procesal, sin embargo, por el principio iura novit curia y el principio de flexibilidad contenido en el artículo noveno, segunda parte, del Código Procesal Civil, debe interpretarse que su recurso de casación se sustenta en la causal del inciso tercero del artículo trescientos ochentiséis del Código Procesal Civil, es decir, la contravención a las normas que garantizan el derecho a un debido proceso. ${ }^{16}$

Por otro lado, la norma de derecho invocada por las partes no debe requerir ser probada por ellas, pues el juez es quien debe conocerla y aplicarla. Así pues, es doctrina reconocida y aceptada que el juez puede, en la esfera del derecho, suplir a las partes aplicando el principio iura novit curia, siempre que actúe dentro de los límites del petitum y de la causa petendi.

Debe señalarse que si bien son resaltables las bondades y ventajas del iura novit curia, hay que ser objetivos e identificar cuándo es inaplicable este principio. Es el caso del siguiente supuesto:

Es carga procesal del ejecutado invocar la causal que sustenta su contradicción, por lo que no puede alegar en su favor la infracción de un acto procesal cuando con su conducta ha propiciado su propia

$15<$ http://dataonline.gacetajuridica.com.pe/CLP/contenidos. dll? $\mathrm{f}=$ templates $\$ \mathrm{fn}=$ default.html $>$.

$16<$ http://dataonline.gacetajuridica.com.pe/CLP/contenidos. dll?f=templates $\$ \mathrm{fn}=$ default.html $>$. 
indefensión, que no puede ser subsanada por el principio de iura novit curia, ya que no es un error de derecho o de nomen juris, sino que la posición del justiciable que tiene en el proceso debe ser cumplida conforme a la ley procesal, pues de lo contrario debe soportar el efecto de su incumplimiento, como es el rechazo de la contradicción. ${ }^{17}$ (Cas. 3568-00-Ica, publicada el 30 de abril del 2001).

Finalmente, coincidimos con Ledesma Narváez cuando afirma:

[...] el empleo de este principio por parte del juez debe operar con prudencia, limitado por la congruencia procesal, esto es, "no puede ir más allá del petitorio infundando su decisión en hechos diversos de los que han sido alegados por las partes". Debe aplicar la norma siempre enmarcada dentro de las situaciones presentadas por las partes que han armado su estrategia sobre la base de normas que a la postre resultan inaplicables (2008: 65).

\section{La aplicación del principio iura novit curia en el arbitraje de derecho}

Conforme a lo desarrollado, consideramos que todos los árbitros, cuando resuelven los conflictos en arbitrajes de derecho, están declarando el derecho que asiste a la parte cuyas pretensiones amparan, pues la emisión del laudo constituye un acto jurisdiccional. Si bien los árbitros califican como jueces privados y/o particulares y el arbitraje se rige por reglas propias, creemos que no pueden escapar de la ética común a todo proceso y que los obliga a respetar las garantías fundamentales, todo lo cual se circunscribe al pleno sometimiento a la Constitución Política.

En ese orden de ideas, participamos del convencimiento de que los árbitros están en la capacidad - es más, afirmamos que tienen el deber- de aplicar el principio iura novit curia para las funciones y dentro de los límites ya señalados.

Como se ha mencionado, si los árbitros hacen uso de la notio y de la vocatio $\mathrm{y}$, sobre todo, de la resolutio, para esta última atribución bien pueden hacer uso del principio iura novit curia, pues están debidamente formados para ello. Esto ya lo aplican gran parte de árbitros.

$17<$ http://dataonline.gacetajuridica.com.pe/CLP/contenidos. dll?f=templates $\$ \mathrm{fn}=$ default.html $>$. 
Un ejemplo es el laudo arbitral de derecho, en mayoría, de 19 de febrero del 2010, ${ }^{18}$ sobre la controversia relacionada con el contrato 0012008-P-PJ, celebrado entre Promotora Interamericana de Servicios S.A.C. y el Poder Judicial, en el que se señaló:

28.- En atención a lo expuesto, el Tribunal tiene en cuenta el artículo VII del Título Preliminar del Código Procesal Civil, que contiene el principio "Iura novit curia", aforismo que literalmente significa que "el Tribunal conoce el derecho".

En aplicación del referido principio, deben enmendarse situaciones que el Tribunal considera como perniciosas en la relación contractual, siendo pertinente también la aplicación del artículo II del Título Preliminar del Código Civil y el artículo 1954 del mismo cuerpo de leyes.

29.- Los artículos señalados de los Códigos Civil y Procesal Civil son aplicables supletoriamente a los procesos arbitrales, y establecen que el juez debe de aplicar el derecho que corresponde al proceso aunque no haya sido invocado por las partes o lo haya sido erróneamente; es decir, dicho precepto se refiere a la invocación o no de las normas jurídicas que sirven de fundamento de las pretensiones esgrimidas por las partes dentro de un proceso (resaltado nuestro).

De todo lo señalado se destaca que el principio iura novit curia se sustenta en la elasticidad o adecuación de los formalismos ritualistas del proceso a las exigencias humanas, sustantivas y constitucionales de la causa. De esa manera, el árbitro - al igual que el juez- podrá subsanar el error cometido por alguna de las partes al invocar erróneamente una norma o al haberla omitido de plano, debido a que se encuentra obligado a resolver la controversia aplicando el derecho y, por tanto, las normas que resulten pertinentes a la resolución de cada caso en particular, con independencia, pero también en observancia de las normas y derechos constitucionalmente reconocidos, los que no puede ser ignorados.

$18<$ http://portal.osce.gob.pe/osce/sites/default/files/Documentos/Arbitraje/Laudos_temas/otros/N\%20045\%20-\%20PROMOTORA\%20INTERAMERICANA\%20DE\%20SERVICIOS\%20S.A.C.\%20-\%20PODER\%20JUDICIAL.pdf>. 


\section{Bibliografía}

Benito Llopis-Llombart, Marco de (2010). El convenio arbitral. Su eficacia obligatoria. Madrid: Civitas/ Thomson Reuters.

Bernardes de Mello, Marcos (1986). Teoria do fato jurídico. 2. a edición. São Paulo.

Bianca, Massimo (1998). Diritto civile. 3. Il Contratto. Milán: Giuffrè.

Bullard González, Alfredo (2011). “Art. 14.- Extensión del convenio arbitral", en Comentarios a la ley peruana de arbitraje. Tomo I. Lima: Instituto Peruano de Arbitraje.

Caivano, Roque (2008). Arbitraje. 2. ${ }^{\text {a }}$ edición. Buenos Aires: Ad-Hoc.

Cantuarias Salaverry, Fernando (2007). Arbitraje comercial y de las inversiones. Lima: UPC.

Cárdenas Quirós, Carlos (1985). “Exposición de motivos y comentarios. Cláusula compromisoria y compromiso arbitral", en Revoredo, Delia (comp.). Código Civil. Volumen VI. Lima: Okura.

Carleo, Roberto (1998). Le vicende soggettive della clausola compromissoria. Turín: Giappichelli.

Castillo Freyre, Mario y Ricardo Vásquez Kunze (2006). “El dominio contractual en el arbitraje". Ius et Veritas 32. Lima.

China, Sergio la (2007). L'arbitrato. Il sistema e l'esperienza. 3. a edición. Milán: Giuffré.

Diener, María Cristina (2002). Il contratto in generale. Milán: Giuffrè.

Díez-Picazo y Ponce de León, Luis (2004). “Forma y contenido del convenio arbitral", en Comentarios a la nueva Ley de Arbitraje 60/2003, de 23 de diciembre. Navarra: Aranzadi.

Falen Incháustegui, Óscar (2009). “El arbitraje obligatorio en el Estado”. Jus. Gestión Pública. Lima: Grijley.

Kundmüller Caminiti, Franz (1999). “Obligatoriedad del arbitraje y otros temas de gestión de conflictos en la Ley de Contrataciones y Adquisiciones del Estado y su reglamento". Themis 39. Lima.

Latorre Boza, Derik (2008). "El arbitraje en la contratación pública", en Ponencias del Congreso Internacional de Arbitraje 2007. Primera parte. Biblioteca de Arbitraje. Volumen 5. Lima: Palestra.

Ledesma Narváez, María Elena (2008). Comentarios al Código Procesal Civil. Tomo I. Lima: Gaceta Jurídica. 
Lohmann Luca de Tena, Guillermo (1987). "El arbitraje", en Para Leer el Código Civil. Volumen 5. Lima: Pontificia Universidad Católica del Perú, Fondo Editorial.

Lorca Navarrete, Antonio María (2002). "Algunas propuestas acerca de la naturaleza jurídica del arbitraje". Advocatus 7. Lima.

Matheus López, Carlos Alberto (2005). “Introducción al convenio arbitral". Actualidad Jurídica 142. Lima: Gaceta Jurídica.

Monroy Gálvez, Juan (2007). “Función supletoria y correctora del juez: el aforismo Iura Novit Curia", en Código Civil comentado. Tomo I. 2. ${ }^{a}$ edición, 1. ${ }^{a}$ reimpresión. Lima: Gaceta Jurídica.

Obando Blanco, Víctor (1997). Estudios de derecho procesal civil. Lima: Editorial San Marcos.

Paladini, Mauro (1992). "Preliminare unilaterale, opzione, opzione di preliminare bilaterale", en Il contratto preliminare. Milán: Giuffrè.

Roppo, Vincenzo (2001). "Il contratto", en Trattato di diritto privato. A cura di Giovanni Iudica y Paolo Zatti. Milán: Giuffrè.

Sacco, Rodolfo y Giorgio de Nova (1996). Il contratto. Tomo II. Turín: UTET.

Silva Vallejo, José Antonio (1985). “El artículo VII del título preliminar del nuevo Código Civil: llave maestra de la teoría general del derecho civil y procesal", en Libro homenaje a José León Barandiarán. Lima: Cultural Cuzco.

Soto Coaguila, Carlos A. (2011). "Art. 13.- Contenido y forma del convenio arbitral", en Comentarios a la ley peruana de arbitraje. Tomo I. Lima: Instituto Peruano de Arbitraje.

Vidal Ramírez, Fernando (2005). El acto jurídico. Lima: Gaceta Jurídica.

Vidal Ramírez, Fernando (2003). “El convenio arbitral”. Derecho PUC 56. Lima: Facultad de Derecho de la Pontificia Universidad Católica del Perú. 